\title{
ESMOLOL AND PERCUTANEOUS CARDIOPULMONARY BYPASS ENHANCE MYOCARDIAL SALVAGE DURING ISCHEMIA IN A DOG MODEL
}

Glenn W. Laub, MD

S. Muralidharan, MD

Jerome Reibman, MD

Javier Fernandez, MD

William A. Anderson, MD

Jiang $\mathrm{Gu}, \mathrm{MD}, \mathrm{PhD}$

Connie Daloisio, BA

Lynn B. McGrath, MD

Lawrence J. Mulligan, $\mathrm{PhD}$
Despite recent advances in techniques of reperfusion for acute myocardial ischemia, myocardial salvage remains suboptimal. $\beta$-Blockers have been shown to limit infarct size during acute ischemia, but their negative inotropic properties have limited their use. Cardiopulmonary bypass is an attractive technique for cardiac resuscitation because it can stabilize a hemodynamically compromised patient and potentially reduce myocardial oxygen consumption. In an attempt to maximize myocardial salvage in the setting of acute ischemia, the combination of esmolol, an ultrashort-acting $\beta$-blocker, with percutaneous cardiopulmonary bypass was evaluated. Four groups of instrumented dogs underwent 2 hours of myocardial ischemia induced by occlusion of the proximal left anterior descending coronary artery, followed by 1 hour of reperfusion. Throughout the period of ischemia and reperfusion, esmolol plus percutaneous cardiopulmonary bypass was compared with esmolol alone, percutaneous cardiopulmonary bypass alone, and control conditions. After the reperfusion period, the extent of infarction of the left ventricle at risk was determined. Four animals had intractable arrhythmias: one in the esmolol plus bypass group, one in the esmolol group, and two in the control group. The extent of infarction of the left ventricle at risk was significantly reduced in the esmolol plus bypass group (30\%) compared with bypass alone (52\%), with esmolol alone $(54 \%)$, and with the control groups $(59 \% ; p<0.05)$. We conclude that in this experimental model the combination of esmolol with bypass improves myocardial salvage after ischemia and reperfusion. (J Thorac Cardiovasc Surg 1996;111:1085-91)
$R^{\mathrm{e}}$ ecent advances in surgical, pharmacologic, and interventional techniques have made rapid reperfusion achievable in the setting of acute myocardial ischemia. Myocardial salvage is frequently suboptimal with even short periods of ischemia, however, resulting in significant myocardial injury. There are several reported strategies to improve

From the Division of Cardiothoracic Surgery, Department of Surgery, Deborah Heart and Lung Center and Deborah Research Institute, Browns Mills, N.J., and the Department of Surgery, UMDNJ-Robert Wood Johnson Medical School, New Brunswick, N.J.

Presented in part at the American College of Chest Physicians, Chicago, October 1992.

Received for publication Jan. 3, 1995; accepted for publication July 3, 1995.

Address for reprints: Glenn W. Laub, MD, Attending Surgeon, Assistant Professor of Surgery, Deborah Heart and Lung Center, Browns Mills, NJ 08015.

Copyright 1996 by Mosby-Year Book, Inc.

$0022-5223 / 96 \$ 5.00+0 \quad \mathbf{1 2 / 1 / 6 7 7 3 5}$ myocardial salvage, including percutaneous cardiopulmonary bypass, infusion of $\beta$-blockers, and intraaortic balloon counterpulsation, but none has been shown to be uniformly effective. ${ }^{1-6}$ Considerable clinical and experimental evidence has demonstrated that $\beta$-blockers can attenuate the extent of myocardial injury during ischemia and reperfusion. ${ }^{5-12}$ Their utility, however, is limited by their negative inotropic properties. Esmolol, an ultrashort-acting $\beta$-blocker, is an attractive agent because its short half-life allows its negative inotropic effects to be rapidly eliminated minutes after the infusion is stopped.

There is considerable interest in the use of cardiopulmonary bypass for resuscitation of patients with cardiac decompensation after failed percutaneous transluminal coronary angioplasty and acute myocardial infarction. ${ }^{13-18}$ Cardiopulmonary bypass decreases myocardial oxygen consumption $\left(\mathrm{MVO}_{2}\right)$ by decreasing afterload and is highly effective at maintaining hemodynamic stability and resuscitat- 
ing patients. ${ }^{4,16}$ The combination of cardiopulmonary bypass with esmolol is attractive because it allows the use of $\beta$-blockade in situations of hemodynamic instability, where it would not be otherwise possible. The aim of this experimental study was to evaluate the effectiveness of the combination of cardiopulmonary support with esmolol to reduce the extent of infarction.

\section{Methods and materials}

All of the experiments were conducted according to the "Guide for the Care and Use of Laboratory Animals" prepared by the National Institute of Laboratory Animal Resources and published by the National Institutes of Health (NIH Publication No. 86-23, revised 1985). Sixteen conditioned mongrel dogs in good health and weighing more than $35 \mathrm{~kg}$ were anesthetized and maintained with an intravenous infusion of sodium pentobarbital. In the supine position, the animals were intubated with $8 \mathrm{~mm}$ cuffed endotracheal tubes and ventilated with volumecycled respirators (Harvard Apparatus, Inc., Memphis, Mass.), initially at a rate of 15 cycles/min and a tidal volume of $15 \mathrm{ml} / \mathrm{kg}$ and then adjusted according to the arterial blood gases. Electrocardiogram and temperature were continuously displayed and recorded (Gould Pressure Recorder, model 2400S; Gould Inc., Test and Measurement Recording Systems Division, Cleveland, Ohio). A Swan-Ganz catheter (American Edwards Laboratories, Santa Ana, Calif.) was inserted through the right jugular vein. A midsternotomy incision was made, and the pericardium was opened and suspended to the chest wall. The left anterior descending coronary artery was identified and encircled proximal to the first diagonal branch with a large silk tie. The animals were anticoagulated with $3 \mathrm{mg} / \mathrm{kg}$ heparin.

Experimental design. The animals were subdivided into four treatment groups. In the control group (C), the animals underwent 2 hours of myocardial ischemia by occlusion of the left anterior descending coronary artery, followed by 1 hour of reperfusion. At the end of the reperfusion period, the animals were killed and underwent infarct analysis. In the esmolol group (E), the animals underwent a similar period of myocardial ischemia and in addition received an infusion of $250 \mathrm{mg}$. $\mathrm{kg}^{-1} \cdot \mathrm{min}^{-1}$ esmolol throughout the myocardial ischemic period, beginning 15 minutes before the ligation of the left anterior descending coronary artery, and $125 \mathrm{mg}$. $\mathrm{kg}^{-1} \cdot \min ^{-1}$ during the reperfusion period. In the cardiopulmonary bypass group (B), the animals were started and maintained on bypass throughout the ischemic period and for 30 minutes of reperfusion and were then weaned from bypass. In the esmolol plus cardiopulmonary bypass group (EB), the animals were given the esmolol as in the $E$ group and were placed on bypass as in the $B$ group. Treatment modalities (esmolol infusion, bypass, or both) were started 15 minutes before ligation of the left anterior descending coronary artery in an attempt to mimic the clinical scenario of a patient with unstable hemodynamics after unsucessful percutaneous translumi- nal coronary angioplasty or a developing myocardial infarction.

Cardiopulmonary support. The left femoral vessels were exposed and a $22 \mathrm{~F}$ heparin-coated percutaneous venous cannula (Cook Incorporated, Bloomington, Ind.) was inserted over a guidewire. The tip of the venous cannula was positioned at the superior cavoatrial junction. The femoral artery was exposed and cannulated directly with an $18 \mathrm{~F}$ percutaneous arterial cannula (Cook). The arterial and venous lines were connected to a perfusion circuit that used a Bio-Medicus BP-80 (Bio-Medicus, Inc., Minneapolis, Minn.) centrifugal pump and Bently BCM 7 oxygenator (Bently Laboratories, Inc., Irvine, Calif:). The circuit was primed with lactated Ringer's solution (Abbott Laboratories, North Chicago, Ill.). Animals were placed on normothermic percutaneous cardiopulmonary bypass at a flow equivalent to a calculated index of $2.2 \mathrm{~L} \cdot \min$. $\mathrm{m}^{-2}$.

Infarct analysis. At the conclusion of the reperfusion period, the animals underwent analysis of infarct size. The left anterior descending coronary artery was resnared, and $5 \mathrm{ml} / \mathrm{kg}$ of $1 \%$ gentian violet was injected into the left atrium. The heart was excised, and the left ventricle was frozen at $-20^{\circ} \mathrm{C}$ for 20 minutes. The ventricle was then sliced in $3 \mathrm{~mm}$ sections, starting at the apex. The slices were then incubated for 15 minutes at $37^{\circ} \mathrm{C}$ and stained with 2,3,5-triphenyl-2H-tetrazolium chloride. The myocardial slices were reincubated and fixed in $10 \%$ formalin. The outlines of the left ventricle, infarcted tissue, normal tissue, and area at risk were traced onto acetate. Areas of interest were calculated from the acetate tracings with a digital planimetry board, and ratios of area of infarct to area at risk (AI/AR) were calculated. The method of staining to delineate the necrotic tissue from ishemic tissue is a well-accepted, commonly used technique. ${ }^{19}$ The chemical used (2,3,5-triphenyl-2H-tetrazolium chloride) stains normal tissue containing dehydrogenase enzymes brick red. Infarcted tissue, depleted of these enzymes, remains pale yellow. Tissue samples from infarcted, atrisk, and normal areas of the left ventricle from each animal were collected for routine histopathologic examination.

Statistical analysis. Significant differences in AI/AR ratios for the four groups were determined by two-way analysis of variance. Post hoc analysis was completed with the Student-Newman-Keuls test, and data were considered significant for $p<0,05$. Differences in heart rate and mean arterial pressure for each respective group were evaluated at each time interval for the four groups by one-way analysis of variance with post hoc analysis completed with the Student-Newman-Keuls test. Data are presented as mean \pm SEM.

\section{Results}

Infarct analysis results are summarized in Table I. Area at risk for infarction and area of infarction did not differ significantly within each group for the animals that survived beyond the 30-minute reperfusion period and for those that died at between 30 and 60 minutes of reperfusion. The area at risk for 
infarction for each group ranged from $36.2 \%$ to $42 \%$ of the left ventricle and did not significantly differ between groups. Group $\mathrm{C}$ had an AI/AR ratio of $59.1 \% \pm 4.9 \%$, whereas groups $\mathrm{E}$ and $\mathrm{B}$ had $\mathrm{AI} / \mathrm{AR}$ ratios of $53.8 \% \pm 1.3 \%$ and $51.7 \% \pm 4.0 \%$, respectively. Group EB exhibited an AI/AR ratio reduced by approximately one half to $29.6 \% \pm 7.6 \%$ ( $p<$ $0.05)$. Normalized heart rates, shown in Fig. 1, were lowest at 60 minutes in group E $(p<0.05)$ compared with the control group and highest at 30 minutes after reperfusion in group B $(p<0.001)$ compared with the control group. Mean arterial pressure (Fig. 2) did not change significantly during the procedure for any groups.

Heart rate and mean arterial pressure are presented in Table II. The parameter of greatest importance was the AI/AR ratio; heart rate and mean blood pressure data, however, provided subtle but independent evidence to reinforce the efficacy of combining esmolol with bypass. Histopathologic examination of hematoxylin and eosin-stained tissue sections confirmed that the infarct analysis was valid. The general arrangement of myocytes in the infarcted areas was disturbed, with edema and increased extracellular spaces. The myocytes were slightly swollen and had disrupted membranes. The association of myocytes was loosened, and leukocytic infiltration was present. In the area at risk there was little evidence of myocardial damage in some noninfarcted portions.

\section{Discussion}

Recent strategies to treat acute myocardial ischemic events have focused on methods of directly reversing the ischemic state by eliminating the obstruction to blood flow through the uise thrombolytic agents, surgery, and angioplasty. Despite these advances in techniques of reperfusion for acute myocardial ischemia, myocardial salvage remains suboptimal. ${ }^{12-18}$ It is unclear why short periods of ischemia followed by rapid reperfusion are not associated with myocardial salvage but rather end in infarction. In an attempt to reduce the extent of infarction associated with ischemia, several strategies have been clinically and experimentally investigated. One of the most promising areas of research into the modulation of the response to ischemia is through $\beta$-blockade.

The $\beta$-blockers have demonstrated a beneficial effect in reducing myocardial damage in the setting of acute ischemia in both clinical and experimental studies; the mechanism through which this occurs,
Table I. Comparison of extent of infarction between groups

\begin{tabular}{lccc}
\hline & $A I(\%)$ & $A R(\%)$ & $A I / A R(\%)$ \\
\hline Control & $21.6 \pm 2.7$ & $36.2 \pm 1.9$ & $59.1 \pm 4.9$ \\
Esmoiol & $19.9 \pm 3.7$ & $37.3 \pm 8.4$ & $53.8 \pm 1.3$ \\
Bypass & $21.8 \pm 2.8$ & $42.0 \pm 4.5$ & $51.7 \pm 4.0$ \\
Esmolol and bypass & $12.5 \pm 4.2$ & $39.8 \pm 3.8$ & $29.6 \pm 7.6^{*}$ \\
\hline
\end{tabular}

Values are mean \pm standard error of the mean. $A I$, Area of left ventricle infarcted; $A R$, area of left ventricle at risk.

" $p<0.05$; significantly different from control, esmolol, and bypass.

however, is not yet completely understood. Several theories have been postulated regarding the protective nature of $\beta$-blockers, including that they exhibit their protective effect by decreasing myocardial metabolic requirements during the ischemic event, that they increase the coronary blood flow and therefore oxygen delivery to the ischemic tissue during or after the ischemic event, ${ }^{18,20}$ and that they render the myocardium more resistant to the effects of ischemia. ${ }^{21-23}$ The $\beta$-blockers have been shown to reduce the myocardial metabolic requirements through both indirect hemodynamic effects and direct cellular effects. The $\beta$-blockers indirectly reduce the energy requirements by decreasing heart rate, mean arterial pressure, contractile state, and the tension development in the ventricle, thus reducing the pressure-related work of the heart. ${ }^{24-26}$ This reduction in work can be seen as a reduction in $\mathrm{MVo}_{2}$ and correlates closely with the left ventricular systolic pressure-volume area, which has also been shown to decrease. ${ }^{27}$

In addition to the indirect hemodynamic effect of $\beta$-blockade, $\beta$-blockers can reduce mitochondrial respiration by inhibition of reduced nicotinamide adenine dinucleotide phosphate oxidase, ${ }^{28}$ inhibit calcium uptake by isolated sarcoplasmic reticulum, ${ }^{29}$ and protect the sarcolemma from ischemic injury. ${ }^{30}$ These direct cellular changes decrease contractile state, myocardial work, and energy requirements. It has also been demonstrated that $\beta$-blockers have several effects on myocardial substrate metabolism. There is evidence that during ischemia, $\beta$-blockade renders the heart less dependent on the use of free fatty acids and more dependent on carbohydrates as metabolic fuel $\mathrm{I}^{28,29,31,32}$ and in addition inhibits phosphorylase activity. ${ }^{33}$ What specific effects these alterations in metabolic activity have on reperfusion injury remains unclear. Furthermore, the cardioprotective nature of $\beta$-blockade may reside in the ability of $\beta$-blockers to reduce free radical-mediated injury. ${ }^{34}$ Ischemic myocardium treated with esmolol has 


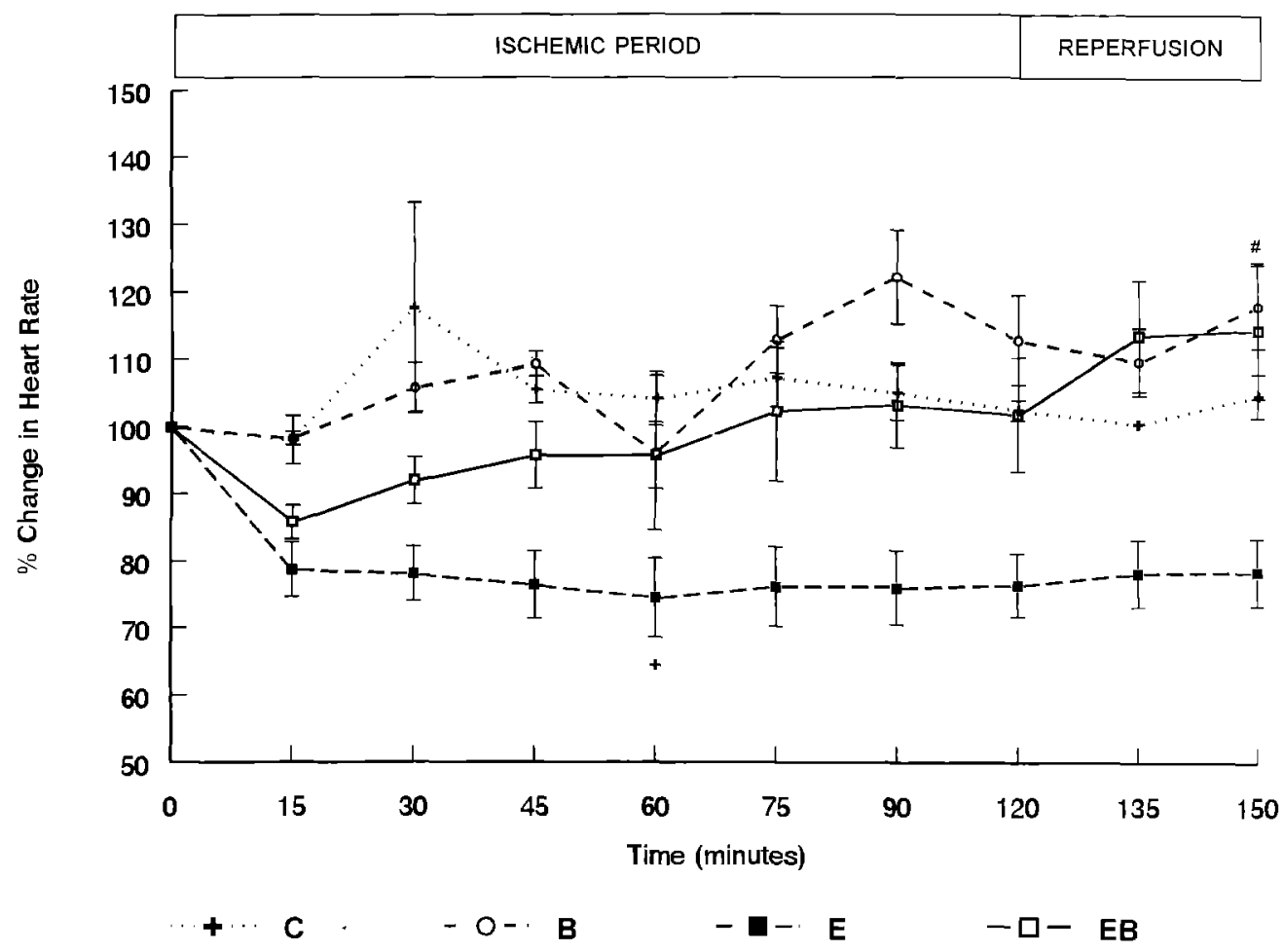

Fig. 1. Percentage change in heart rate as a function of baseline values during ischemia and reperfusion.,$+ p<0.05$ vs control by analysis of variance; \#, $p<0.001$ vs control by analysis of variance.

been shown to have lower levels of lipid peroxidation, a marker of myocardial membrane injury, than seen in untreated regions of the left ventricle. ${ }^{9}$

We chose to use esmolol, an ultrashort-acting agent, because of its clinical safety. The safety of this agent is due not only to the rapid reversibility of its effects with discontinuation of administration but also to the ease of titration of action, which allows rapid adjustment to meet changing patient needs. This is particularly useful in patients with myocardial ischemia, for whom optimizing the oxygen supply-demand ratio is essential but among whom heart failure, conduction abnormalities, and hypotension are frequent clinical problems. Despite the potential benefits, the use of $\beta$-blockers in the setting of acute ischemia is limited by their inherent negative inotropic nature. In addition, the hemodynamic status during periods of ischemia may already be tenuous and thus preclude the use of $\beta$-blockers. In an effort to overcome these limitations, we attempted to support the systemic circulation with cardiopulmonary bypass while administering $\beta$-blockers. Another potential benefit of cardiopulmonary bypass is that it treats the hemodynamic instability associated with ischemic myocardial failure, promoting hemodynamic stabilization and whole-body resuscitation. ${ }^{5}$ Other agents have been used in an attempt to improve postbypass left ventricular function. Additives or substrates have typically been combined with cardiopulmonary bypass in the setting of acute ischemia. These include metabolic substrates such as glutamate or aspartate, ${ }^{35,36}$ oxygen free-radical scavengers, ${ }^{37}$ and nitric oxide donors such as L-arginine. ${ }^{38}$ Significant reductions in myocardial injury have been acheived with free-radical scavengers and nitric oxide donors. Although these agents have been shown to improve postreperfusion left ventricular function, they have not been uniformly successful in all models of ischemiareperfusion because of several factors. For an additive to be useful in the majority of experimental and clinical studies, the additive must be able to prevent to some degree myocardial oxidative stress, to prevent ischemic injury to the myocytes and endothelial cells, or to protect the myocardium from reperfusion injury. An additive that can meet these requirements has not yet been found. Nonetheless, although the exact mechanism through which esmolol protects the myocardium from reperfusion injury or decreases infarct size remains unknown, it is clear that a cardioprotective effect exists. 


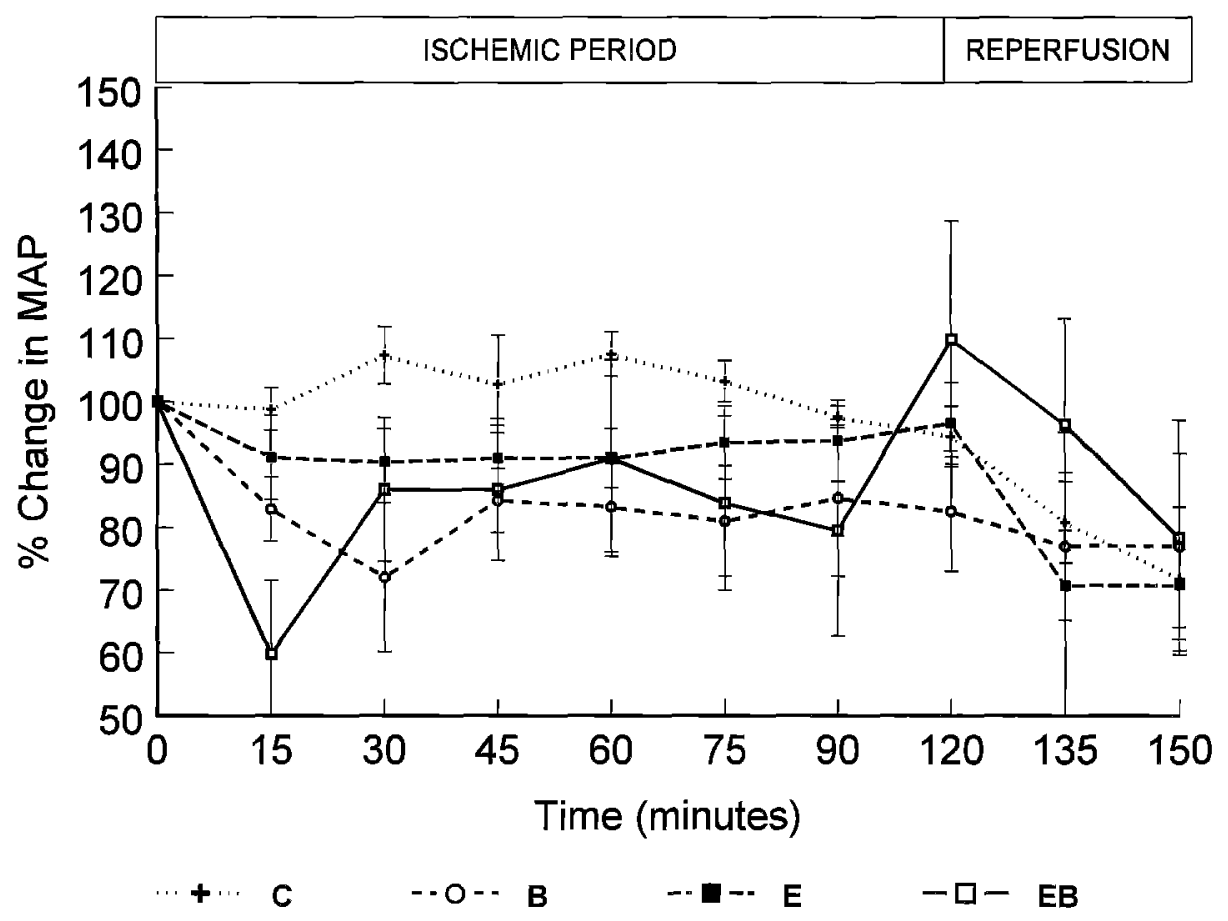

Fig. 2. Percentage change in mean arterial pressure as a function of baseline values during ischemia and reperfusion.

Table II. Mean arterial pressures and heart rates during baseline, occlusion, and reperfusion

\begin{tabular}{|c|c|c|c|c|c|c|c|c|c|c|}
\hline \multirow[b]{2}{*}{ Group } & \multirow[b]{2}{*}{ Baseline } & \multicolumn{7}{|c|}{ Time after ligation (min) } & \multicolumn{2}{|c|}{ Time after reperfusion (min) } \\
\hline & & 15 & 30 & 45 & 60 & 75 & 90 & 120 & 15 & 30 \\
\hline \multicolumn{11}{|c|}{ Mean arterial pressure $(\mathrm{mm} \mathrm{Hg})$} \\
\hline C & $103 \pm 14$ & $100 \pm 15$ & $110 \pm 14$ & $110 \pm 10$ & $111 \pm 14$ & $104 \pm 15$ & $102 \pm 14$ & $97 \pm 13$ & $89 \pm 8$ & $83 \pm 3$ \\
\hline $\mathrm{E}$ & $106 \pm 5$ & $94 \pm 12$ & $93 \pm 10$ & $93 \pm 7$ & $94 \pm 6$ & $94 \pm 5$ & $95 \pm 6$ & $97 \pm 5$ & $93 \pm 6$ & $94 \pm 9$ \\
\hline B & $98 \pm 14$ & $84 \pm 16$ & $81 \pm 19$ & $88 \pm 14$ & $86 \pm 14$ & $84 \pm 13$ & $74 \pm 15$ & $75 \pm 9$ & $73 \pm 8$ & $65 \pm 5$ \\
\hline $\mathrm{EB}$ & $88 \pm 12$ & $51 \pm 12$ & $74 \pm 12$ & $75 \pm 13$ & $79 \pm 15$ & $73 \pm 16$ & $69 \pm 17$ & $93 \pm 17$ & $82 \pm 17$ & $68 \pm 21$ \\
\hline \multicolumn{11}{|c|}{ Heart rate (beats/min) } \\
\hline $\mathrm{C}$ & $136 \pm 13$ & $134 \pm 14$ & $156 \pm 10$ & $143 \pm 11$ & $141 \pm 8$ & $145 \pm 9$ & $142 \pm 8$ & $139 \pm 12$ & $137 \pm 13$ & $141 \pm 15$ \\
\hline$E$ & $148 \pm 14$ & $117 \pm 13$ & $115 \pm 12$ & $111 \pm 11$ & $107 \pm 10^{*}$ & $109 \pm 12$ & $108 \pm 9$ & $110 \pm 8$ & $103 \pm 5$ & $103 \pm 5$ \\
\hline $\mathrm{B}$ & $143 \pm 12$ & $141 \pm 12$ & $141 \pm 14$ & $156 \pm 13$ & $141 \pm 26$ & $160 \pm 9$ & $173 \pm 6$ & $168 \pm 9$ & $168 \pm 11$ & $185 \pm 4 \dagger$ \\
\hline $\mathrm{EB}$ & $134 \pm 5$ & $112 \pm 5$ & $119 \pm 7$ & $123 \pm 9$ & $125 \pm 9$ & $134 \pm 14$ & $132 \pm 10$ & $136 \pm 13$ & $144 \pm 13$ & $143 \pm 16$ \\
\hline
\end{tabular}

Values represent mean \pm standard error of the mean.

$* p<0.05$ vs control by analysis of variance.

$\dagger p<0.001$ vs control by analysis of variance.

We chose percutaneous cannulation of the arterial and venous system because traditional cardiopulmonary bypass necessitates a major surgical procedure with cannulation of the great vessels in the chest. $^{5}$ This is a time-consuming technique that requires specialized equipment and training to perform. In an effort to improve implementation of cardiopulmonary bypass in the setting of acute cardiac situations, percutaneous access is desirable.
Although previous studies have evaluated the cardioprotection associated with $\beta$-blockers or percutaneous cannulation to stabilize systemic hemodynamic and perfusion requirements, these treatments have not been investigated in combination. 5, 6, 9-11 Our study was directed at evaluating the use of percutaneous cannulation of the arterial and venous system to resuscitate, stabilize, and support the patient - and possibly to reduce infarct size-and to 
combine these benefits with the pharmacologic benefits of $\beta$-blockade. In addition to its role for hemodynamic support, cardiopulmonary bypass has been used in several experimental models to $\mathrm{MVO}_{2}$ and infarct size. Although several studies have demonstrated decreases in $\mathrm{MVo}_{2}$, significant increases have also been observed. ${ }^{39-41}$ The greatest benefit from cardiopulmonary bypass has been shown with pulsatile perfusion systems, with either pulsatile bypass or a combination of nonpulsatile bypass with an intraaortic balloon pump. ${ }^{1,6} \mathrm{We}$ did not use pulsatile assist in this study because currently available pulsatile bypass devices are not commercially available and are cumbersome to work with.

In our study, we were able to demonstrate a reduction in infarct size with the use of esmolol plus percutaneous cardiopulmonary bypass (Table I). We did not attempt to delineate the mechanism by which this myocardial salvage occurred, but we did observe that during the combination of esmolol and bypass mean arterial pressure was reduced from control values throughout the ischemic period, while heart rate remained unchanged. This observation supports the concept that the beneficial combination of esmolol with percutaneous bypass is from the reduction in afterload and protection from reflexmediated increases in pressure and heart rate, thereby resulting in a lower myocardial energy expenditure during ischemia and thus leading to a smaller infarct.

\section{Conclusion}

The combination of ultra-short acting $\beta$-blockers with cardiopulmonary bypass is theoretically attractive because it provides a way of reducing myocardial damage during periods of ischemia while providing mechanical circulatory assist to aid in resuscitation and circulatory support. Our experimental experience demonstrates a significant reduction in extent of infarction when these modalities are combined. This combined approach of bypass and $\beta$-blockade appears to be a promising area for further research, with important clinical ramifications.

We appreciate the helpful suggestions of our statistician, C. Chen, PhD.

\section{REFERENCES}

1. Axelrod H, Galloway A, Murphy M, et al. Percutaneous cardiopulmonary bypass with a synchronous pulsatile pump combines effective unloading with ease of application. $J$ Thorac Cardiovasc Surg 1987;93:358-65.
2. Kirshenbaum JM, Kloner RA, Antman E, Braunwald E. Use of an ultrashort-acting beta blocker in patients with acute myocardial ischemia: hemodynamic and electrical consequences. Circulation 1985;72:873-80.

3. Lange R, Kloner RA, Braunwald E. First ultra-short-acting beta-adrenergic blocking agent: its effect on size and segmental wall dynamics of reperfused myocardial infarcts in dogs. Am J Cardiol 1983;51:1759-67.

4. Wessln O, van der Linden J, Ekroth R, et al. Influence of $\mathrm{b}_{1}$-blockade on myocardial substrates early after a coronary operation. Ann Thorac Surg 1992;54:1151-8.

5. Laub GW, Muralidharan S, Gu J, et al. Novel system for percutaneous cardiopulmonary bypass. J Invest Surg 1991;4: 217-30.

6. Lazar HL, Treanor P, Yang XM. Enhanced recovery of ischemic myocardium by combining percutaneous bypass with intraaortic balloon pump support. Ann Thorac Surg 1994;57:663-7.

7. Kloner RA, Fishbein MC, Braunwald E, Maroko PR. Effect of propranolol on mitochondrial morphology during acute myocardial ischemia. Am J Cardiol 1978;41:880-6.

8. Kloner RA, Kirshenbaum J, Lange R, Antman EM, Braunwald E. Experimental and clinical observations on the efficacy of esmolol in myocardial ischemia. Am J Cardiol 1985;56: $40 \mathrm{~F}-8 \mathrm{~F}$.

9. Roth E, Torok B. Effect of ultrashort-acting beta-blocker Brevibloc on free-radical-mediated injuries during the early perfusion period. Basic Res Cardiol 1991;86:422-33.

10. Sidi A, Rush W. Decreased regional lactate production and output due to intracoronary continuous infusion of esmolol during acute coronary occlusion in dogs. J Cardiothorac Vasc Anesth 1991;5:237-42.

11. Spahn DR, Frasco PE, White WD, Smith R, McRae RL, Leone BJ. Esmolol cardioprotective? Tolerance of pacing tachycardia, acute afterloading and hemodilution in dogs with coronary stenosis. J Am Coll Cardiol 1993;21:809-21.

12. ISIS-3 (Third International Study of Infarct Survival) Collaborative Group. ISIS-3: a randomized comparison of streptokinase vs tissue plasminogen activator vs anistreplase and of aspirin plus heparin vs aspirin alone among 41,229 cases of suspected acute myocardial infarction. Lancet 1992;339:75370.

13. Laub GW, Banaszak D, Kupferschmid J, Magovern GJ, Young JC. Percutaneous cardiopulmonary bypass for the treatment of hypothermic circulatory collapse. Ann Thorac Surg 1989;47:608-11.

14. Phillips SJ, Ballentine B, Slonine D, et al. Percutaneous initiation of cardiopulmonary bypass. Ann Thorac Surg 1983; 36:223-5.

15. Mooney MR, Arom KV, Joyce LD, et al. Emergency cardiopulmonary bypass support in patients with cardiac arrest. J Thorac Cardiovase Surg 1991;101:450-4.

16. Simoons ML, Arnold AE, Betriu A, et al. Thrombolysis with tissue plasminogen activator in actute myocardial infarction: no additional benefit from immediate percutaneous coronary angioplasty. Lancet 1988;1:197-203.

17. TIMI Research Group. Immediate vs delayed catheterization and angioplasty following thrombolytic therapy for acute myocardial infarction: TIMI ILA results. JAMA 1988;260; 2849-58.

18. TIMI Study Group. Comparison of invasive and conservative strategies after treatment with intravenous tissue plasmino- 
gen activator in acute myocardial infarction: results of the thrombolysis in myocardial infarction (TIMI) phase II trial. N Engl J Med 1989;320:618-27.

19. Fishbein MC, Meerbaum S, Rit $\mathbf{J}$, et al. Early phase acute myocardial infarct size quantification: validation of the triphenyl tetrazolium chloride tissue enzyme staining technique. Am Heart J 1981;101:593-600.

20. Buck JD, Hardman HF, Warltier DC, Gross GJ. Changes in ischemic blood flow distribution and dynamic severity of a coronary stenosis induced by beta blockade in the canine heart. Circulation 1981;64:708-15.

21. Warltier DC, Gross GJ, Hardman HF. Effect of propranolol on regional myocardial blood flow and oxygen consumption. J Pharmacol Exp Ther 1976;198:435-43.

22. Jennings RB, Reimer KA. Fate of the ischemic myocardial cell. In: Corday E, Swan HJ, eds. New perspectives in diagnosis and management of myocardial infarction. Baltimore: Williams \& Wilkins, 1973:13-25.

23. Reimer KA, Rasmussen MM, Jennings RB. Reduction by propranolol of myocardial necrosis following temporary coronary artery occlusion in dogs. Circ Res 1973;33:353-63.

24. Tomoike H, Ross J Jr, Franklin D, Crozatier B, McKown D, Kemper WS. Improvement by propranolol of regional myocardial dysfunction and abnormal coronary flow pattern in conscious dogs with coronary narrowing. Am J Cardiol 1977:41:689-96.

25. Vatner SF, Baig M, Manders T, Ochs H, Pagani M. Effects of propranolol on regional function, electrograms, and blood flow in conscious dogs with myocardial ischemia. J Clin Invest 1977;60:353.

26. Braunwald E, Sobel BE. Coronary blood flow and myocardial metabolis. In: Braunwald E, ed. Heart disease: a textbook of cardiovascular medicine. Philadelphia: WB Saunders, 1992: $1161-200$

27. Suga H. Ventricular energetics. Physiol Rev 1990;70:247-77.

28. Sakurade A, Voss DO, Brando D, Campello AP. Effects of propranolol on heart muscle mitochondria. Biochem Pharmacol 1972;21:535-40.

29. Hess ML, Briggs FN, Shinebourne E, Hamer J. Effect of adrenergic blocking agents on the calcium pump of the fragmented cardiac sarcoplasmic reticulum. Nature 1972;220:79-80.

30. Marchetti G, Merlo L, Noseda V. Myocardial uptake of free fatty acids and carbohydrates after beta-adrenergic blockade. Am J Cardiol 1968;22:370-4.
31. Masters TN, Glaviano VV. Effects of norepinephrine and propranolol on myocardial subcellular distribution of triglycerides and free fatty acids. J Pharmacol Exp Ther 1972;182: 246-55.

32. Wollenberger A, Krause EG, Heier G. Stimulation of $3^{\prime}, 5^{\prime}-$ cyclic AMP formation in dog myocardium following arrest of blood flow. Biochem Biophys Res Commun 1969;36:664-70.

33. Nakamura R. Effects of adenaline and cyanide on myocardial fatty acid metabolism. Kumamoto Med J 1973;24:10-9.

34. Freedman AM, Kramer JH, Mak IT, Cassidy MM, Weglicki WB. Propranolol preserved ultrastructure in adult myocytes exposed to anoxia/reoxygenation: a morphometric analysis. Free Radical Biol Med 1991;11:197-206.

35. Rosenkranz ER, Okamoto F, Buckberg GD, et al. Aspartate enrichment of glutamate blood cardioplegia in energy-depleted hearts after ischemic and reperfusion injury: safety of prolonged aortic clamping with blood cardioplegia. J Thorac Cardiovasc Surg 1986;91:428-35.

36. Lazar HL, Buckberg GD, Manganaro AM. Myocardial energy replenishment and reversal of ischemic damage by substrate enhancement of secondary blood cardioplegia with amino acids during reperfusion. J Thorac Cardiovasc Surg 1980;80:350-9.

37. Vinten-Johansen J, Chiantella V, Johnston WE, et al. Adjuvant $\mathrm{N}$-(2-mercaptopropionyl)-glycine in the blood cardioplegia does not improve myocardial protection in ischemically damaged hearts. J Thorac Cardiovasc Surg 1990;100:65-76.

38. Nakanishi K, Zhao ZQ, Vinten-Johansen J, Hudspeth DA, McGee, S, Hammond JW. Blood cardioplegia enhanced with nitric oxide donor SPM- 5185 counteracts postischemic endothelial and ventricular dysfunction. J Thorac Cardiovasc Surg 1995;109:1146-54.

39. Furukawa S, Bavaria JE, Kreiner G, Edmunds LH. Relationship between total mechanical energy and oxygen consumption in the stunned myocardium. Ann Thorac Surg 1990;49: 543-9.

40. Furukawa S, Kreiner G, Bavaria JE, Streicher JT, Edmunds LH. Recovery of oxygen utilization efficiency after global myocardial ischemia. Ann Thorac Surg 1991;52:1063-8.

41. Bavaria JE, Furukawa S, Kreiner G, et al. Myocardial oxygen utilization after reversible global ischemia. $\mathbf{J}$ Thorac Cardiovasc Surg 1990;100:210-20. 